\title{
Marginal zone lymphoma-derived interfollicular diffuse large B-cell lymphoma harboring 20q12 chromosomal deletion and missense mutation of BIRC3 gene: a case report
}

\author{
Joseph Hatem ${ }^{1}$, April M. Schrank-Hacker ${ }^{1}$, Christopher D. Watt ${ }^{1}$, Jennifer J. D. Morrissette ${ }^{1}$, Adam I. Rubin²,
} Ellen J. Kim², Sunita D. Nasta ${ }^{3}$, Mariusz A. Wasik ${ }^{1}$ and Agata M. Bogusz ${ }^{1 *}$

\begin{abstract}
Background: Diffuse large B-cell lymphoma (DLBCL) typically leads to effacement of the nodal architecture by an infiltrate of malignant cells. Rarely ( $<1 \%)$, DLBCL can present with an interfollicular pattern (DLBCL-IF) preserving the lymphoid follicles. It has been postulated that DLBCL-IF is derived from marginal zone B cells and may represent a large-cell transformation of marginal zone lymphoma (MZL), however no direct evidence has been provided to date. Here we describe a rare case of a diagnostically challenging DLBCL-IF involving a lymph node in a patient with a prior history of lymphadenopathy for several years and MZL involving skin.

Case presentation: A 53-year old man presented to our Dermatology Clinic due to a 1-year history of generalized itching, fatigue of 2-3 month's duration, nausea and mid back rash that was biopsied. PET (positron emission tomography)/CT (computed tomography) was performed and revealed inguinal, pelvic, retroperitoneal, axillary, and cervical lymphadenopathy. The patient was referred to surgery for excisional biopsy of a right inguinal lymph node. Diagnostic H\&E stained slides and ancillary studies were reviewed for the lymph node and skin specimens. B-cell clonality by PCR and sequencing studies were performed on both specimens.

We demonstrate that this patient's MZL and DLBCL-IF are clonally related, strongly suggesting that transformation of MZL to DLBCL had occurred. Furthermore, we identified a novel deletion of the long arm of chromosome 20 (del(20q12)) and a missense mutation in BIRC3 (Baculoviral IAP repeat-containing protein 3) in this patient's DLBCL that are absent from his MZL, suggesting that these genetic alterations contributed to the large cell transformation. Conclusions: To our knowledge, this is the first report providing molecular evidence for a previously suspected link between MZL and DLBCL-IF. In addition, we describe for the first time del(20q12) and a missense mutation in BIRC3 in DLBCL. Our findings also raise awareness of DLBCL-IF and discuss the diagnostic pitfalls of this rare entity.
\end{abstract}

Keywords: Diffuse large B-cell lymphoma (DLBCL) with deletion 20q(del(20q)), Interfollicular diffuse large B cell lymphoma (DLBCL-IF), Marginal zone lymphoma

\footnotetext{
* Correspondence: Agata.Bogusz@uphs.upenn.edu

'Department of Pathology and Laboratory Medicine, Hospital of the

University of Pennsylvania, 7 E Gates Pavilion, 3400 Spruce Street,

Philadelphia 19104-4283, PA, USA

Full list of author information is available at the end of the article
} 


\section{Background}

Diffuse large B-cell lymphoma (DLBCL), the most common type of non-Hodgkin lymphoma, is defined as a neoplasm of large B lymphocytes that display a diffuse growth pattern [1]. DLBCL is a quite diverse group of malignancies with respect to cell morphology, pathogenesis, clinical presentation, and therapeutic response [13]. Gene expression profiling studies identified two major subgroups of nodal DLBCL based on the "cell of origin": the germinal center (GC) B-cell-like DLBCL (GCB DLBCL) and the prognostically less favorable activated B-cell-like DLBCL (ABC DLBCL) [4]. Immunohistochemical signatures were developed to translate the molecular signatures and distinguish between the GCB DLBCL and non-GCB DLBCL [5].

The World Health Organization (WHO) classification distinguishes numerous subtypes of DLBCL [1]. In the majority of the cases, DLBCL leads to effacement of the nodal architecture by a diffuse infiltrate of malignant cells. Rarely, however, DLCBL can show an interfollicular pattern (DLBCL-IF) of proliferation, preserving the lymphoid follicles [6]. These cases constitute only about $1 \%$ of all DLBCL, frequently display a polymorphous appearance microscopically due to the admixture of nonneoplastic inflammatory cells, and often present a diagnostic challenge. Previous reports indicate that DLBCLIF are predominantly of non-GCB type $[6,7]$. Interestingly, the interfollicular large $B$ cells in normal lymph node also show a non-GCB phenotype and share some immunophenotypic characteristics with monocytoid B cells [8]. It has been postulated that DLBCL-IF is derived from marginal zone $\mathrm{B}$ cells and may represent a largecell transformation of an underlying MZL [7], however, no direct evidence has been provided to date. The overall survival rate and prognosis of the DLBCL-IF seems to be better than that of a non-IF DLBCL as control group (DLBCL-CG) as the majority of cases present in stage 1 or 2, show significantly lower International Prognostic Index (IPI) scores than the DLBCL-CG [6]. Consequently, it has been previously suggested that DLBCLIF is a distinct clinicopathologic entity [7].

In the case described here, we provide a direct evidence genetically linking DLBCL-IF and MZL. Furthermore, we identify a novel $\operatorname{del}(20 \mathrm{q} 12)$ and a BIRC3 missense mutation in DLBCL-IF, but not the patient's preceding MZL involving skin, strongly suggesting that these genomic alterations are at least in part responsible for the large cell transformation.

\section{Materials and methods}

\section{Histology and immunohistochemistry}

Formalin-fixed paraffin-embedded tissue sections were stained with hematoxylin and eosin (H\&E). Immunohistochemical stains were performed on $4 \mu \mathrm{m}$ tissue sections using an Autostainer (Leica BOND platform, Buffalo Grove, IL) according to manufacturer's instructions. Sections were deparaffinized in xylene and graded alcohols. Detection of the antibodies was performed using a chromogenic substrate, diaminobenzene (DAKO). The following antibodies were used: CD1a, CD3, CD5, CD10, CD20, CD23, CD30, CD79a, BCL6, Oct-2, BOB.1 (all from Leica), CD2, CD8, BCL2, CD45, CD68, CD138, CD163, MUM-1/IRF4, ALK, Ki67, p53 (all from Dako), BCL1 (Fisher), c-MYC (Epitomics), PAX5 and CD15 (both BD Bioscience), CD4 (Biocare), CD56 (Zymed/Invitrogen), CD57 (Thermofisher), PD-1 (Abcam), TIA1 (Immunotech), and panCK (Biogenex),

\section{Molecular analysis for clonality}

DNA was extracted from either fresh tissue (i.e., skin) or paraffin embedded (i.e., lymph node) tissue. PCR amplification was subsequently performed using two sets of fluorescently-labeled primers (InVivoScribe Technologies) that hybridize to a conserved V-framework (i.e., FR2 or FR3) region and the conserved J-region of immunoglobulin heavy chain $(I G H)$ gene. The PCR products were size separated by capillary electrophoresis on a 3500xL Genetic Analyzer (Life Technologies). Data were analyzed (GeneMapper v5.0 software) and then reviewed for peak patterns consistent with a clonal expansion.

\section{Fluorescence in situ hybridization (FISH) analysis}

FISH was performed on $3 \mu \mathrm{m}$ formalin-fixed paraffin embedded sections using the Vysis LSI D20S108 (20q12) SpectrumOrange probe and the Vysis CEP 8 (D8Z2, 8p11.1-8q11.1 alpha satellite) SpectrumGreen (Abbott Molecular Laboratories, Abbott Park, IL), according to the manufacturers' instructions. In brief, slides were deparaffinized using xylene incubation $(\times 3)$, followed by ethanol wash steps $(100,70 \%)$. Prior to hybridization the slides were treated with Dako Pre-Treatment solution (Dako, Inc K5799) followed by digestion with pepsin $\left(37{ }^{\circ} \mathrm{C}, 15 \mathrm{~min}\right)$. Slides were dehydrated in ethanol (70, $85,100 \%)$, dried and the FISH probes were added and incubated overnight. The following morning the slides were washed, counterstained with DAPI and manually visualized and scored.

\section{Gene mutation analysis}

Detection of single nucleotide variants (SNVs) and insertions/deletions (indels) analysis of paraffin-embedded skin and lymph node tissue samples was performed by the University of Pennsylvania clinical genomics laboratory, the Center for Personalized Diagnostics. The genes sequenced were part of a custom, targeted nextgeneration sequencing amplicon panel for 68 hematologic malignancy-associated genes (TruSeq Custom Amplicon, Illumina Inc.) based on previously 
described analyses [9, 10]. Briefly, individual library preparations were pooled and concurrently sequenced on the Illumina MiSeq (Illumina, Inc.). To assure a minimum read depth of $250 \times$, the mean depth of coverage across the entire panel was 2000x. Detection of SNVs was validated to a $4 \%$ allele frequency and large indels to a $1 \%$ allele frequency. A separate assay was performed in parallel to sequence the CEBPA gene using long range PCR to isolate the gene and library preparation was performed using the tagmentation-based Nextera library preparation kit (Illumina, Inc.). The CEBPA gene was sequenced in tandem with the hematologic nextgeneration sequencing panel and reported together with the custom heme-NGS panel.

A custom bioinformatics pipeline was utilized to detect alterations [11]. Manual review of the data including visualization of variants was performed on all samples following bioinformatics processing variants, with variants compared with our knowledgebase and on-line databases for further curation, using human reference sequence UCSC build hg 19 (NCBI build 37.1) for comparison. Single nucleotide polymorphisms (SNPs) with a minor allele frequency (MAF) > $0.1 \%$ were considered benign and were not reported; these calls were based on the Exome Variant Server (http://evs.gs.washington.edu/EVS), the ExAC browser (http://exac.broadinstitute.org) and dbSNP. Reported variants used nomenclature based on the Human Genome Variation Society nomenclature guidelines (http://www.hgvs.org/mutnomen) and internally categorized into five different categories (benign, likely benign, variant of uncertain significance, likely pathogenic, pathogenic); the categories likely benign, variant of uncertain significance and likely pathogenic were reported as variants of uncertain significance in the electronic health record.

\section{Flow cytometry}

Flow cytometry was performed on representative tissue from the inguinal lymph node using the FACSCantoII flow cytometer from BD Immunosystems. Samples were prepared by aliquoting $50-75 \mu \mathrm{L}$ of prepared cell suspension into reagent tubes. Twenty microliter of rabbit blocking reagent was added to the $\mathrm{B}$ cell clonality tube and allowed to incubate at $37{ }^{\circ} \mathrm{C}$ for $20 \mathrm{~min}$ and $20 \mu \mathrm{L}$ of rabbit serum was added to the remainder of the tubes. Laboratory prepared and premixed antibody cocktail was added in $20 \mu \mathrm{L}$ aliquots to each designated tube and allowed to incubate in the dark for 20 to $30 \mathrm{~min}$. The cells were then washed with 3 to $5 \mathrm{ml}$ of wash buffer that was added to each tube, followed by centrifuging at $1450 \mathrm{rpm}$ for $5 \mathrm{~min}$ at $10{ }^{\circ} \mathrm{C}$. The cell pellet was resuspended in $0.5 \mathrm{ml}$ of wash buffer and $10 \mu \mathrm{L}$ of DAPI working solution was added to each tube. Data is then acquired on the flow cytometer.

\section{Case presentation Clinical findings}

A 53-year-old man was evaluated in our Dermatology Clinic due to a 1-year history of generalized itching, fatigue of 2-3 month's duration, nausea over the past month, and a new left mid back rash. A physical exam was essentially unremarkable except for a $1.2 \mathrm{~cm}$ red/ purple plaque on the left mid back that was biopsied. Basic blood work was within normal limits. PET/CT was performed and revealed inguinal, pelvic, retroperitoneal, axillary, and cervical lymphadenopathy. The patient was referred to surgery for excisional biopsy of a right inguinal lymph node. Of note, a CT scan performed 4 years earlier had demonstrated inguinal lymphadenopathy (3.8 $\mathrm{cm}$ lymph node). No additional workup was done at that time. A follow-up CT scan performed 2 years later showed mildly prominent bilateral axillary lymphadenopathy. One year prior to the current evaluation, the patient noted swelling in the right and left axilla.

\section{Pathologic findings \\ Skin biopsy}

The H\&E-stained sections demonstrated a dense nodular lymphoid infiltrate in the superficial and deeper dermis without involvement of the epidermis (Fig. 1a). The infiltrate was composed of predominantly small lymphocytes with scattered larger transformed cells with immunoblast morphology (Fig. 1b). Immunohistochemical stains demonstrated nodules of CD20 positive B cells around and within follicles, with scattered larger interfollicular B cells also present (Fig. 1c). CD3 stain highlighted abundant interfollicular T lymphocytes (not shown). Essentially all neoplastic B cells as well as many of the interfollicular $\mathrm{T}$ cells were positive for BCL2 (Fig. 1d). BCL6 was negative in the tumor cells. The findings were consistent with cutaneous involvement by marginal zone lymphoma.

\section{Excisional biopsy of the right inguinal lymph node}

The H\&E stained sections showed a lymph node with an overall well-preserved nodal architecture including reactive lymphoid follicles with well-demarcated mantle zones (Fig. 2a). The interfollicular zones were, however, expanded by numerous large atypical mononuclear cells admixed with abundant eosinophils, small lymphocytes, plasma cells and histiocytes (Fig. 2a and b). The larger cells had oval to slightly irregular nuclear contours, vesicular chromatin, prominent nucleoli, and scant to moderate amount of clear to amphophilic cytoplasm (Fig. 2c and $\mathrm{d}$ ). Immunohistochemical stains showed that the large cells were positive for B-cell markers CD20 

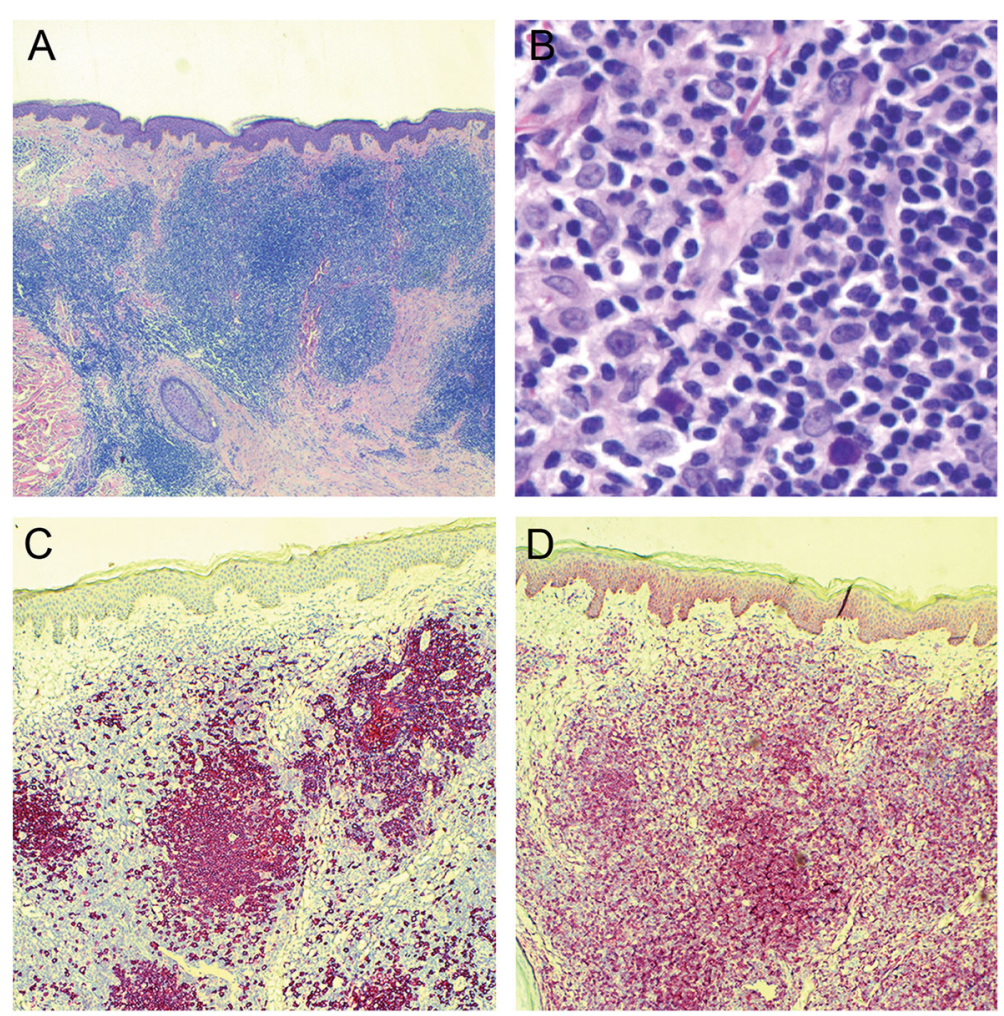

Fig 1 Histological findings of the skin biopsy from initial presentation. a Low magnification (25x) demonstrating a nodular infiltrate in the superficial and deeper dermis (H\&E). b At higher power (400X) the majority of the cells are small and have irregular nuclei and inconspicuous nucleoli. There are scattered large transformed immunoblasts (H\&E). c CD20 stain highlights the nodules of B lymphocytes (CD20

immunohistochemical stain, 50x) d The B lymphocytes in the nodules are positive for BCL2 (BCL2 immunohistochemical stain, 50x)

(Fig. 2e), PAX5 (Fig. 2f), and CD79a, as well as BCL6 (subset), CD30 (Fig. 2g), MUM1(Fig. 2h), CD23, c-MYC (40-50\%), p53 (dim in 40\% of the large cells), BOB.1 (variable) and Oct-2 (variable). The Ki-67 proliferation index in the interfollicular areas was high, exceeding 70\%. Key negative stains included BCL2, CD10, and CD15. CD138 highlighted plasma cells with a kappa to lambda ratio of 3:1. An in-situ hybridization study for Epstein-Barr virus (EBER) was negative. CD20, PAX5 and CD79a stains also marked the abundant reactive follicles with $\mathrm{CD} 10+, \mathrm{BCL} 6+$ and BCL2- germinal centers and BCL2+ mantle zones. The proliferation index within the germinal centers was high as expected $(>90 \%)$ and highlighted the polarized light and dark zones. The infiltrating small $\mathrm{T}$ lymphocytes were positive for $\mathrm{CD} 2, \mathrm{CD} 3, \mathrm{CD} 5$ and $\mathrm{CD} 7$ (major subset). The CD4 to CD8 ratio was increased (>5:1). CD57 and PD-1 were positive in a subset of germinal center $\mathrm{T}$ cells whereas TIA1, perforin, and granzyme $\mathrm{B}$ were positive in scattered small interfollicular $\mathrm{T}$ cells with a pattern similar to CD8 staining. CD56 and ALK-1 stains were negative. CD68, CD163, and CD1a stained scattered histiocytes and accessory cells respectively.

\section{Ancillary studies on the lymph node specimen}

Flow cytometry studies were performed on representative tissue from the right inguinal lymph node. As shown in Fig. 3a-c, there was a large population of CD19+ B lymphocytes (51\% of all lymphoid cells) with a strong lambda bias bordering on overt restriction (kappa: lambda ratio of 0.33 and 0.27 for the CD19+ and CD20+ cells, respectively). Minor subsets of all B lymphocytes were CD5+ (Fig. 3a) or CD10+ (Fig. 3d); these cells expressed predominantly kappa and, hence, were not part of the apparent lambda clone.

Molecular studies for IGH gene rearrangement performed on the skin biopsy showed a 281 base pair (bp) peak in framework 2, as well as 94 bp and 115 bp peaks in framework 3 (Fig. 4). Examination of tissue obtained from the right inguinal lymph node demonstrated the same 281 bp peak in framework 2 and the same $115 \mathrm{bp}$ peak in framework 3 whereas the 94 bp peak seen in the skin specimen was not seen in the lymph node (Fig. $4 \mathrm{~b}$ ). The overall results indicate that the lymphoproliferative disorders involving lymph node and skin are clonally related. The significance of the $94 \mathrm{bp}$ peak is unclear, but it may represent a separate (sub-)clonal expansion. No 

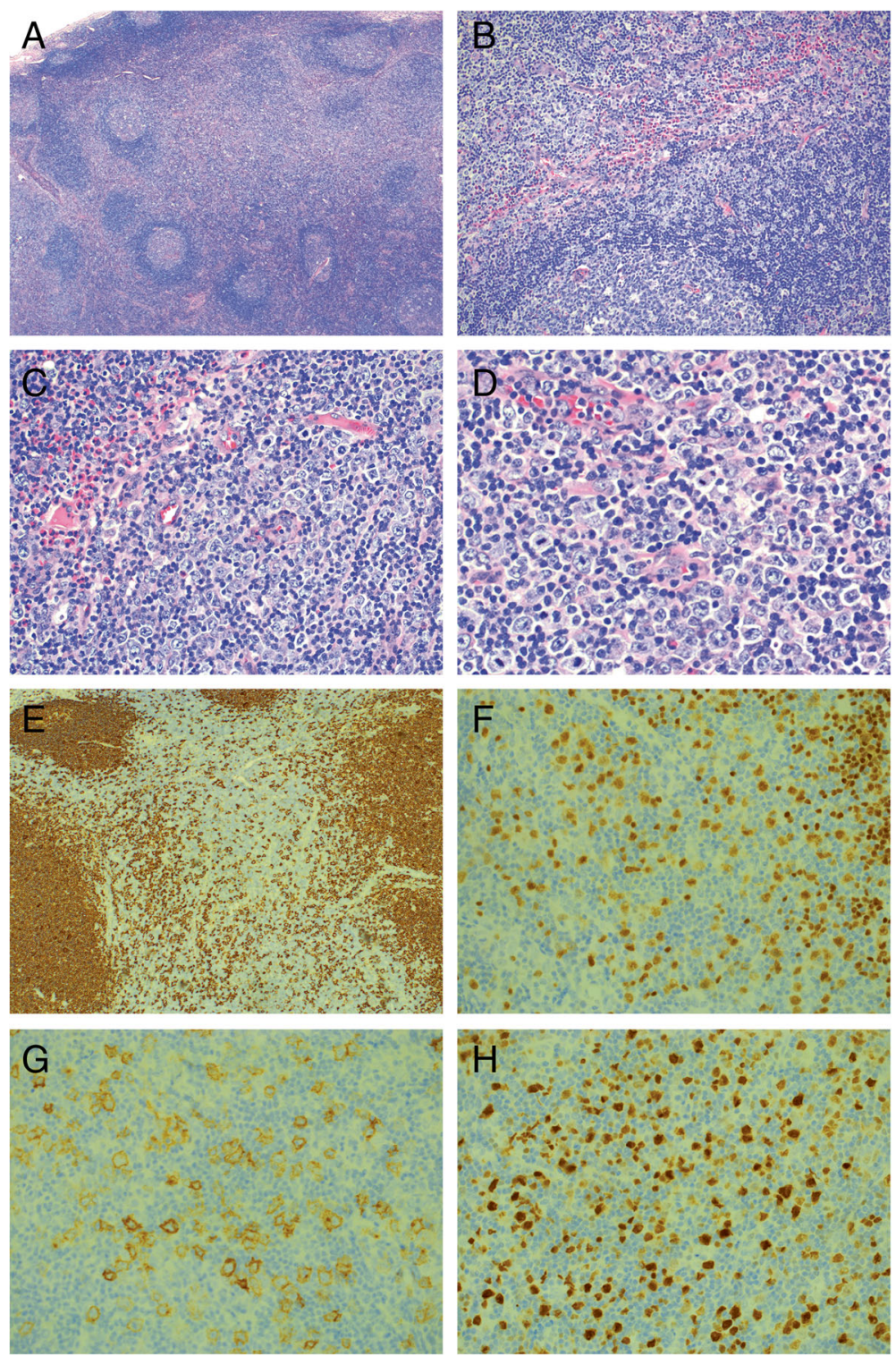

Fig. 2 Histological findings of the inguinal lymph node excision 2 weeks after initial presentation. a Low-power view (25x) shows a lymph node with a preserved architecture with intact capsule, patent sinuses and polarized germinal centers with well-demarcated mantle zones. The interfollicular areas are expanded (H\&E). b At higher magnification (100X) the interfollicular infiltrate is composed of numerous large transformed immunoblasts in the background of small lymphocytes, abundant eosinophils, scattered plasma cells and histiocytes (H\&E). c At 200x magnification (H\&E) and (D) at 400x magnification the large atypical cells have large oval to slightly irregular nuclei with vesicular chromatin, prominent nucleoli and scant to moderate amounts of clear to amphophilic cytoplasm (H\&E). e The large atypical cells are immunoreactive for CD20 (CD20 immunostain, 50X) as well as for f PAX5 (PAX5 immunostain, 200x), g CD30 (CD30 immunostain, 200x) and h MUM1 (MUM1 immunostain, 200x)

clonal T-cell receptor (TCR) rearrangement was detected in the lymph node specimen.

FISH studies for rearrangements of MYC, BCL2, and BCL6 performed on the lymph node were also negative. Previous report described del(20q) in MZL with aggressive features [12]. Since this patient's DLBCL was thought be derived from a MZL, additional FISH analysis for a 20q12 deletion was performed on both skin and lymph node material to determine whether this abnormality may be present. The analysis revealed that $38 / 150(25.3 \%)$ of cells in the involved lymph node were harboring del(20q12) (Fig. 5), whereas the skin lesion was negative for this deletion (data not shown).

Targeted DNA sequencing studies using our hematologic malignancy panel on the lymph node tissue did not reveal any known disease-associated mutations, however it did identify two variants of uncertain significance (Table 1): a missense variant in BIRC3 (Baculoviral 

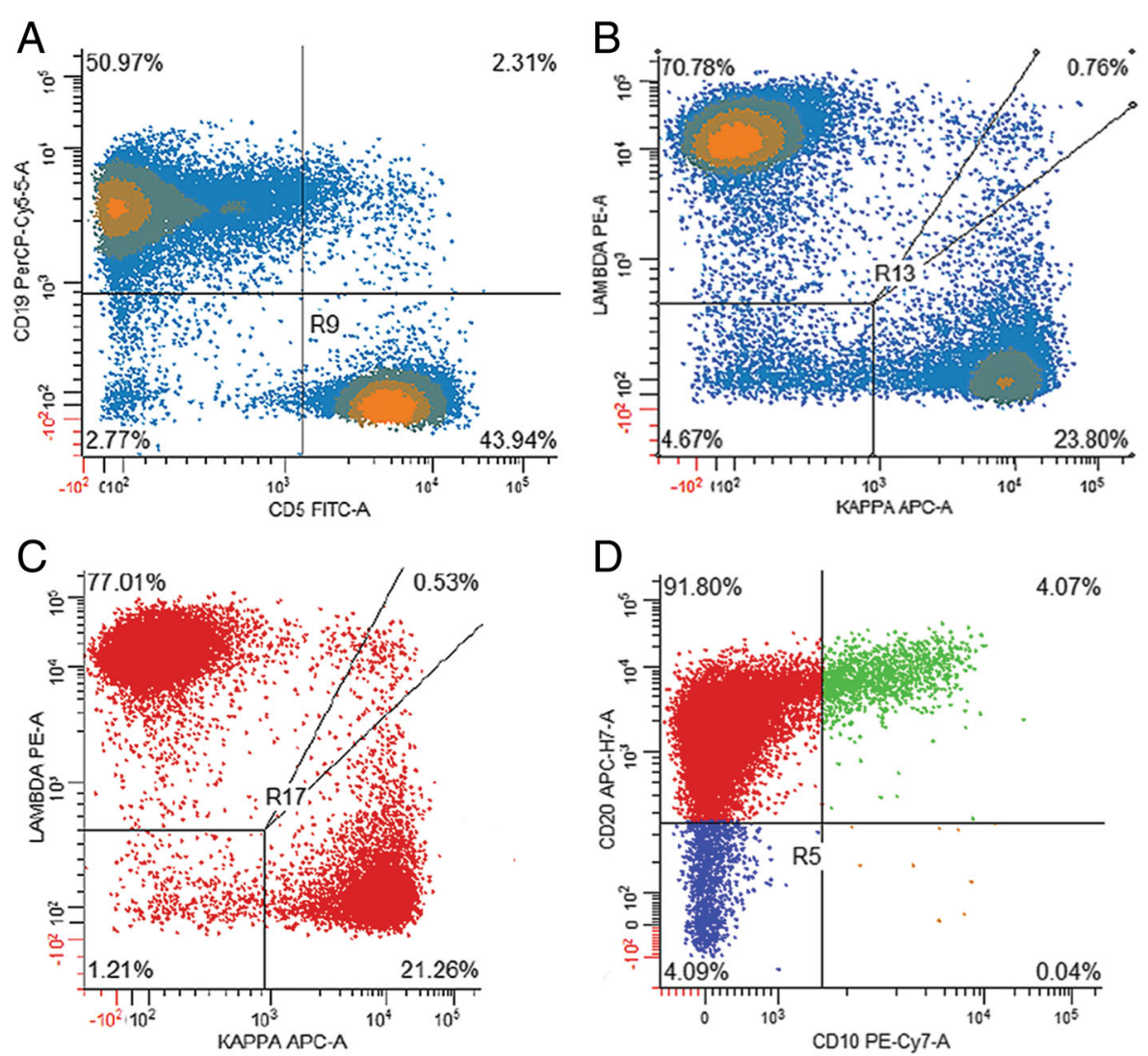

Fig. 3 Flow cytometric analysis of representative tissue from the inguinal lymph node. a The CD19/CD5 plot demonstrates and admixture of CD19-positive B cells and CD5-positive T cells. $\mathbf{b}$ Gating on the CD19 positive B cells demonstrates a clear lambda bias. $\mathbf{c}$ the lambda bias of is also seen when gating on CD20 positive B cells. $\mathbf{d}$ The majority of the CD19 positive B cells were found to be CD20 positive and CD10 negative. The presence of a subset of CD10 positive B cells and subset positivity for kappa light chain staining is compatible with germinal center B cells that are admixed with the malignant $B$ cells

IAP repeat-containing protein 3 ) at amino acid 572 converting the wild type residue, cysteine, to tyrosine in BIRC3 (p.C572Y $\rightarrow$ c.1715G $>$ A) in 491 reads out of a total 9155 sequence reads for an allele frequency of $5.36 \%$ and a missense variant in EZH2 gene (Enhancer of Zeste Homolog 2) at amino acid 322 converting the wild type residue, Asparagine, to Serine (p.N322S $\rightarrow$ c. $965 \mathrm{~A}>\mathrm{G}$ ) in 818 reads out of a total 1561 sequence reads for an allele frequency of $52.40 \%$. Subsequent sequencing studies of the skin revealed the same missense variant in $E Z H 2$ as in the lymph node in 1097 reads out of a total 2165 sequence reads for an allele frequency of

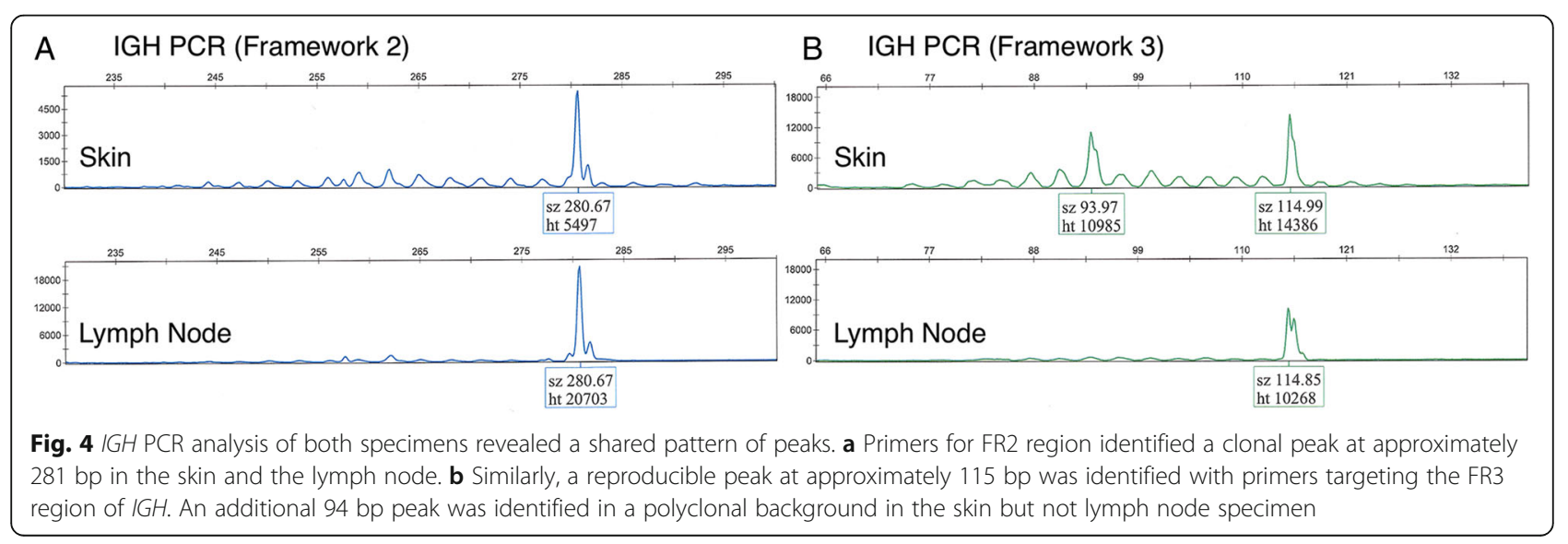



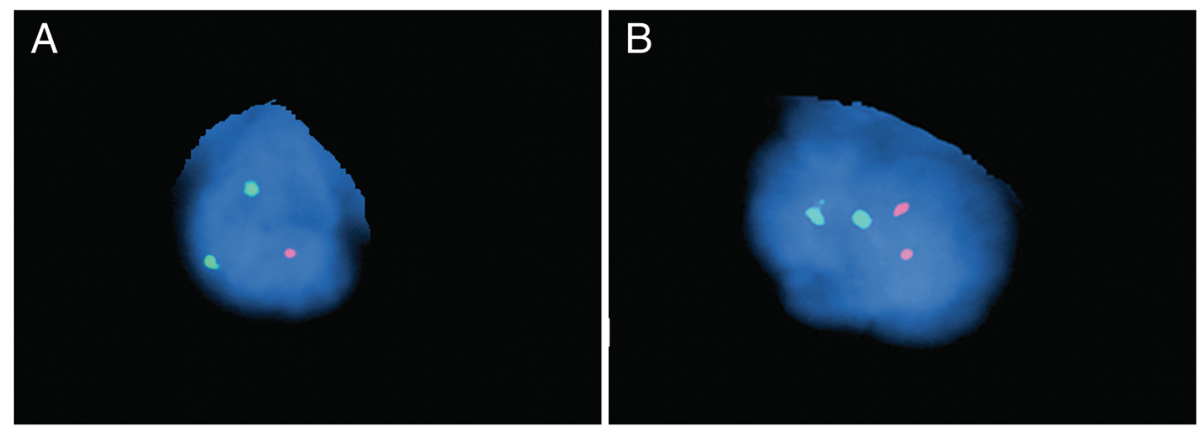

Fig. 5 FISH analysis of the lymph node specimen. Representative images of FISH analysis of the lymph node specimen using probes specific for chromosome 20 (20q12, red) and centromere of chromosome 8 (green). a Cell positive for del(20q) and b cell negative for del(20q)

$50.67 \%$ but no other alterations, including the BIRC3 mutation, were identified.

\section{Discussion}

We report a rare case of a DLBCL with an interfollicular pattern of involvement (DLBCL-IF) with sparing of the nodal architecture including lymphoid follicles. This pattern is common in peripheral T-cell lymphoma, not otherwise specified (PTCL, NOS) that shows proliferation of malignant cells in the paracortex [1]. Our case showed that the large malignant cells were admixed with an inflammatory infiltrate including abundant eosinophils. It has been reported that approximately $60 \%$ of DLBCL-IF cases contain reactive inflammatory cells that are admixed with the large cells, a feature that is frequently seen also in PTCL, NOS $[1,6,7]$. Thus, DLBCLIF can mimic histological picture of PTCL, NOS and it is of utmost importance to be aware of this entity, as PTCL-NOS carries a worse prognosis than DLBCL-IF and calls for different therapeutic approaches. Therefore, immunohistochemistry studies are required to differentiate between these two entities. It is important to keep in mind that both these types of lymphoma can be immunoreactive for CD30. Furthermore, it is critical to always consider DLBCL-IF in the differential diagnosis of atypical interfollicular proliferations. Since distinguishing it from a reactive interfollicular hyperplasia may be sometimes difficult, given the abundant background of inflammatory cells often seen in this type of lymphoma, additional ancillary testing including IGH gene rearrangement studies and flow cytometry may prove particularly useful to establish the diagnosis.

It has been postulated that DLBCL-IF may be derived from marginal zone $\mathrm{B}$ cells and may represent a large- cell transformation of a MZL $[7,8]$. To date, however, there was no direct evidence to confirm this hypothesis. Here we show for the first time a direct link between a MZL and DLBCL-IF by demonstrating the presence of the same clonal $I G H$ rearrangement in the patient's skin and nodal biopsies. Furthermore we identified del(20q12) in the DLBCL-IF. This genetic abnormality has not been reported to date in a DLBCL of any kind. Deletion of chromosome 20q is a common cytogenetic abnormality in various myeloid neoplasms, most notably myelodysplastic syndrome $[1,13,14]$ but its association with lymphoid malignancies is rare and limited to a few reports. This includes a case of lymphoplasmacytic lymphoma/Waldenström macroglobulinemia [15] and two cases of marginal zone lymphoma $[12,16]$. Another study of 64 patients with chronic lymphocytic leukemia (CLL) revealed that del(20q) appears to be a therapyrelated abnormality in CLL involving both myeloid and lymphoid cells and may represent disease progression $[17,18]$. Given that del(20q12) in this patient was identified in the lymph node and not skin lesion and that the patient has not received any prior chemotherapy at that time, this abnormality is likely related to transformation of MZL to DLBCL and implicates a loss of important gene(s) likely with tumor suppressor function. Potential candidate genes that map to this region include $M Y B L 2$ [19], Dido [20], L3MBTL1 [21] and SAMHD1 [22].

Next-generation sequencing studies using a custom panel of 68 hematologic malignancy-associated genes revealed the same missense variant in EZH2 in both the skin and lymph node specimen and a missense variant in BIRC3 that was present only in the lymph node specimen. The $E Z H 2$ variant was listed in all three databases searched at very low allele frequencies (5 cases in

Table 1 Summary of identified missense variants in the lymph node and skin biopsy specimens

\begin{tabular}{|c|c|c|c|c|}
\hline Gene alteration & Protein change & Nucleotide change & Frequency in lymph node & Frequency in skin \\
\hline BIRC3 & C572Y & c.1715G > A & $5.36 \%$ & $0 \%$ \\
\hline$E Z H 2$ & N322S & $c .965 \mathrm{~A}>\mathrm{G}$ & $52.40 \%$ & $50.67 \%$ \\
\hline
\end{tabular}

Abbreviations: $A$ adenine, $C$ cysteine, $c$. coding, $G$ guanine, $N$ asparagine, $p$. protein, $S$ serine, $Y$ tyrosine 
COSMIC, in 4/13002 alleles in the exome variant server, and 37/121,370 alleles in the ExAC database).

The missense variant in BIRC3 (p.C572Y $\rightarrow$ c.1715G > A), not reported in any of the three databases searched (see methods section), was detected only in the lymph node but not skin specimen at an allele frequency of 5.36\%. Morphologic examination revealed that the tumor comprises about $10-15 \%$ of the lymph node specimen. When these two observations are taken together, the data imply that the BIRC3 mutation may be present in a heterozygous state within the neoplasm (i.e., a tumor burden of approximately $10 \%$ with a heterozygous mutation would be expected to generate an allelic burden of approximately $5 \%$ ). So, even though this variant has not been previously described, the circumstantial evidence implies this is an oncogenic mutation that occurred in the malignant DLBCL-IF cells.

The fact that this mutation was only seen in the lymph node and not in the skin biopsy strongly suggests that it may have contributed to transformation of this patient's MZL to DLBCL. BIRC mutations are not among the recurrent mutations in the "standard" DLBCL according to a recent report [23]. BIRC3 gene located on chromosome 11 at 11q22.2 encodes cIAP2 (cellular inhibitor of apoptosis 2), that acts as an E3 ubiquitin ligase that regulates NF-kappa-B signaling and affects a variety of cell functions including apoptosis, proliferation and immune modulation [24, 25]. Of note, proteins from the IAP family are potential therapeutic targets in hematological malignancies [26]. BIRC3 mutations have been identified in various small $B$ cell lymphomas including chronic lymphocytic leukemia (CLL) and splenic marginal zone lymphoma (SMZL) $[27,28]$. More recent studies demonstrate the role of the ubiquitin ligases, both cIAP2 and a closely structurally related cIAP1, encoded by the BIRC2 gene, in NF- $\mathrm{KB}$ signaling triggered by the $\mathrm{B}$ cell receptor (BCR) in DLBCL cells [29].

The alteration in EZH2 gene (p.N322S $\rightarrow$ c.965A > G) was observed with an allele frequency of approximately $50 \%$ in both specimens and this most likely represents a benign/low-oncogeneic potential polymorphism rather than a highly oncogenic mutation. EZH2 gene on 7q36 encodes the histone methyltransferase which initiates epigenetic silencing of genes [30] and plays a role in normal B cell development [31]. EZH2 is mutated in a variety of tumors including lymphomas and targeting of EZH2 protein with specific inhibitors show promising results in preclinical studies and early clinical trials [32$34]$. Interestingly, it has been reported that EZH2 polymorphisms may contribute to susceptibility of tumor development and predict overall survival in some cancers [35-38] and may have also contributed to progression of the disease in this patient.

\section{Conclusions}

In summary, we present a rare case of diagnostically challenging DLBCL with an interfollicular pattern and provide data that support the hypothesis that DLBCL-IF can arise from a MZL. To our knowledge, this represents the first reported case where DLBCL-IF and MZL are shown to be clonally related. We identify a novel del20q and a BIRC3 missense mutation in this patient's DLBCL-IF that have not been previously reported in DLBCL. Given the absence of both these genetic abnormalities in the patient's MZL, they both may have contributed to the large cell transformation.

\section{Abbreviations}

ABC DLBCL: Activated B-cell-like DLBCL; BCR: B-cell receptor; BIRC3: Baculoviral IAP repeat-containing protein 3; CIAP2: Cellular inhibitor of apoptosis 2; CLL: Chronic lymphocytic leukemia; CT: Computed tomography; del(20q): Deletion 20q; DLBCL: Diffuse large B-cell lymphoma; DLBCL-IF: Interfollicular diffuse large B-cell lymphoma; EZH2: Enhancer of zeste homolog 2; FISH: Fluorescence in situ hybridization; GCB DLBCL: Germinal center (GC) B-cell-like DLBCL; IGH: Immunoglobulin heavy chain; IPI: International prognostic index; MZL: Marginal zone lymphoma; PET: Positron emission tomography; PTCL, NOS: Peripheral T-cell lymphoma, not otherwise specified; WHO: The World Health Organization

\section{Acknowledgements}

Not applicable.

\section{Funding}

The author(s) received no financial support for this publication.

\section{Availability of data and materials}

The histological specimens and the corresponding data belong to the Department of Pathology and Dermatology of the University of Pennsylvania and are available upon request for review by the Editor-in-Chief.

\section{Authors' contributions}

$J H$ and AMB drafted the manuscript; CDW, JJDM, AIR, EJK, SDN and MAW revised the manuscript. AMB finalized the manuscript. ASH performed FISH studies (Fig. 5). CDW analyzed the molecular data (Fig. 4). JJDM analyzed genetic data (Table 1). All authors read and approved the final manuscript.

\section{Competing interests}

The authors declare that they have no competing interests.

\section{Consent for publication}

Written informed consent for publication of their clinical details and/or clinical images was obtained from the patient. A copy of the consent form is available for review by the Editor of this journal.

Ethics approval and consent to participate

Not applicable.

\section{Author details \\ 'Department of Pathology and Laboratory Medicine, Hospital of the University of Pennsylvania, 7 E Gates Pavilion, 3400 Spruce Street, Philadelphia 19104-4283, PA, USA. ²Department of Dermatology, University of Pennsylvania, Philadelphia 19104, PA, USA. ${ }^{3}$ Department of Medicine, University of Pennsylvania, Philadelphia 19104, PA, USA.}

Received: 29 September 2016 Accepted: 23 November 2016 Published online: 19 December 2016

\section{References}

1. Swerdlow Sh CE, Harris NL, Jaffe ES, Pileri SA, Stein H, Thiele J, Vardiman J. WHO classification of tumours of haematopoietic and lymphoid tissues, vol 4th edition. World Health Organization and classification of tumours. Lyon: International Agency for Research on Cancer (IARC); 2008. 
2. Carbone A, Gloghini A, Kwong YL, Younes A. Diffuse large B cell lymphoma: using pathologic and molecular biomarkers to define subgroups for novel therapy. Ann hematol. 2014;93(8):1263-77. doi:10.1007/s00277-014-2116-y.

3. Gifford GK, Gill AJ, Stevenson WS. Molecular subtyping of diffuse large B-cell lymphoma: update on biology, diagnosis and emerging platforms for practising pathologists. Pathology. 2016;48(1):5-16. doi:10.1016/j.pathol.2015. 11.017.

4. Alizadeh AA, Eisen MB, Davis RE, Ma C, Lossos IS, Rosenwald A, Boldrick JC, Sabet H, Tran T, Yu X, Powell Jl, Yang L, Marti GE, Moore T, Hudson Jr J, Lu L, Lewis DB, Tibshirani R, Sherlock G, Chan WC, Greiner TC, Weisenburger DD, Armitage JO, Warnke R, Levy R, Wilson W, Grever MR, Byrd JC, Botstein D, Brown PO, Staudt LM. Distinct types of diffuse large B-cell lymphoma identified by gene expression profiling. Nature. 2000;403(6769):503-11. doi: 10.1038/35000501

5. Hans CP, Weisenburger DD, Greiner TC, Gascoyne RD, Delabie J, Ott G, Muller-Hermelink HK, Campo E, Braziel RM, Jaffe ES, Pan Z, Farinha P, Smith LM, Falini B, Banham AH, Rosenwald A, Staudt LM, Connors JM, Armitage JO, Chan WC. Confirmation of the molecular classification of diffuse large Bcell lymphoma by immunohistochemistry using a tissue microarray. Blood. 2004;103(1):275-82. doi:10.1182/blood-2003-05-1545.

6. Yamauchi A, Ikeda J, Nakamichi I, Kohara M, Fukuhara S, Hino M, Kanakura Y, Ogawa H, Sugiyama H, Kanamaru A, Aozasa K, Osaka Lymphoma Study G. Diffuse large B-cell lymphoma showing an interfollicular pattern of proliferation: a study of the Osaka Lymphoma Study Group. Histopathology. 2008;52(6):731-7. doi:10.1111/j.1365-2559.2008.03018.x.

7. Wada N, Zaki MA, Kohara M, Ogawa H, Sugiyama H, Nomura S, Matsumura I, Hino M, Kanakura Y, Inagaki H, Morii E, Aozasa K. Diffuse large B cell lymphoma with an interfollicular pattern of proliferation shows a favourable prognosis: a study of the Osaka Lymphoma Study Group. Histopathology. 2012;60(6):924-32. doi:10.1111/j.1365-2559.2011.04161.x.

8. Marafioti T, Jones M, Facchetti F, Diss TC, Du MQ, Isaacson PG, Pozzobon M, Pileri SA, Strickson AJ, Tan SY, Watkins F, Mason DY. Phenotype and genotype of interfollicular large B cells, a subpopulation of lymphocytes often with dendritic morphology. Blood. 2003;102(8):2868-76. doi:10.1182/ blood-2003-03-0692.

9. Sloan CE, Luskin MR, Boccuti AM, Sehgal AR, Zhao J, Daber RD, Morrissette J, Luger SM, Bagg A, Gimotty PA, Carroll M. A modified integrated genetic model for risk prediction in younger patients with acute myeloid leukemia. Plos one. 2016;11(4):e0153016. doi:10.1371/journal.pone.0153016.

10. Patel JP, Gonen M, Figueroa ME, Fernandez H, Sun Z, Racevskis J, Van Vlierberghe P, Dolgalev I, Thomas S, Aminova O, Huberman K, Cheng J, Viale A, Socci ND, Heguy A, Cherry A, Vance G, Higgins RR, Ketterling RP, Gallagher RE, Litzow M, van den Brink MR, Lazarus HM, Rowe JM, Luger S, Ferrando A, Paietta E, Tallman MS, Melnick A, Abdel-Wahab O, Levine RL. Prognostic relevance of integrated genetic profiling in acute myeloid leukemia. N engl j med. 2012;366(12):1079-89. doi:10.1056/NEJMoa1112304.

11. Daber R, Sukhadia S, Morrissette JJ. Understanding the limitations of next generation sequencing informatics, an approach to clinical pipeline validation using artificial data sets. Cancer genet. 2013;206(12):441-8. doi:10. 1016/j.cancergen.2013.11.005

12. Kern JB, Duff DJ, Odem JL, Esebua M, Smith LR, Doll D, Wang M. A novel del(20q) in aggressive nodal marginal zone lymphoma. Case rep pathol. 2013;2013:784176. doi:10.1155/2013/784176

13. Asimakopoulos FA, Green AR. Deletions of chromosome $20 \mathrm{q}$ and the pathogenesis of myeloproliferative disorders. Br j haematol. 1996;95(2):219-26.

14. Pellagatti A, Boultwood J. The molecular pathogenesis of the myelodysplastic syndromes. Eur j haematol. 2015;95(1):3-15. doi:10.1111/ejh.12515.

15. Liu YC, Miyazawa K, Sashida G, Kodama A, Ohyashiki K. Deletion (20q) as the sole abnormality in waldenstrom macroglobulinemia suggests distinct pathogenesis of 20q11 anomaly. Cancer genet cytogenet. 2006;169(1):6972. doi:10.1016/j.cancergencyto.2006.03.013.

16. Pradhan D, Amin RM, Jones MW, Surti U, Parwani AV. Giant cell arteritis of the female genital tract with occult temporal arteritis and marginal zone lymphoma harboring novel 20q deletion: a case report and literature review. Int j surg pathol. 2016;24(1):78-84. doi:10.1177/1066896915605165.

17. Yin CC, Tang G, Lu G, Feng X, Keating MJ, Medeiros LJ, Abruzzo LV. Del(20q) in patients with chronic lymphocytic leukemia: a therapy-related abnormality involving lymphoid or myeloid cells. Mod pathol. 2015:8:11307. doi:10.1038/modpathol.2015.58.

18. Yin CC, Peng J, Li Y, Shamanna RK, Muzzafar T, Dinardo C, Khoury JD, Li S, Medeiros LJ, Wang SA, Tang G. Clinical significance of newly emerged isolated del(20q) in patients following cytotoxic therapies. Mod pathol. 2015;28(8):1014-22. doi:10.1038/modpathol.2015.66.

19. Heinrichs S, Conover LF, Bueso-Ramos CE, Kilpivaara O, Stevenson K, Neuberg D, Loh ML, Wu WS, Rodig SJ, Garcia-Manero G, Kantarjian HM, Look AT. MYBL2 is a sub-haploinsufficient tumor suppressor gene in myeloid malignancy. Elife. 2013;2:e00825. doi:10.7554/eLife.00825.

20. Futterer A, Campanero MR, Leonardo E, Criado LM, Flores JM, Hernandez JM, San Miguel JF, Martinez AC. Dido gene expression alterations are implicated in the induction of hematological myeloid neoplasms. J clin invest. 2005;115(9):2351-62. doi:10.1172/JCl24177.

21. Gurvich N, Perna F, Farina A, Voza F, Menendez S, Hurwitz J, Nimer SD. L3MBTL1 polycomb protein, a candidate tumor suppressor in del(20q12) myeloid disorders, is essential for genome stability. Proc natl acad sci u s a. 2010;107(52):22552-7. doi:10.1073/pnas.1017092108.

22. Clifford R, Louis T, Robbe P, Ackroyd S, Burns A, Timbs AT, Wright Colopy G, Dreau H, Sigaux F, Judde JG, Rotger M, Telenti A, Lin YL, Pasero P, Maelfait J, Titsias M, Cohen DR, Henderson SJ, Ross MT, Bentley D, Hillmen P, Pettitt A, Rehwinkel J, Knight SJ, Taylor JC, Crow YJ, Benkirane M, Schuh A. SAMHD1 is mutated recurrently in chronic lymphocytic leukemia and is involved in response to DNA damage. Blood. 2014;123(7):1021-31. doi:10.1182/blood2013-04-490847.

23. Pasqualucci L, Trifonov V, Fabbri G, Ma J, Rossi D, Chiarenza A, Wells VA, Grunn A, Messina M, Elliot O, Chan J, Bhagat G, Chadburn A, Gaidano G, Mullighan CG, Rabadan R, Dalla-Favera R. Analysis of the coding genome of diffuse large B-cell lymphoma. Nat genet. 2011;43(9):830-7. doi:10.1038/ng.892.

24. Vaux DL, Silke J. IAPs, RINGs and ubiquitylation. Nat rev mol cell biol. 2005; 6(4):287-97. doi:10.1038/nrm1621.

25. Silke J, Vucic D. IAP family of cell death and signaling regulators. Methods enzymol. 2014:545:35-65. doi:10.1016/B978-0-12-801430-1.00002-0.

26. Smolewski $\mathrm{P}$, Robak T. Inhibitors of apoptosis proteins (IAPs) as potential molecular targets for therapy of hematological malignancies. Curr mol med. 2011;11(8):633-49.

27. Rossi D, Fangazio M, Rasi S, Vaisitti T, Monti S, Cresta S, Chiaretti S, De Giudice I, Fabbri G, Bruscaggin A, Spina V, Deambrogi C, Marinelli M, Fama R, Greco M, Daniele G, Forconi F, Gattei V, Bertoni F, Deaglio S, Pasqualucci L, Guarini A, Dalla-Favera R, Foa R, Gaidano G. Disruption of BIRC3 associates with fludarabine chemorefractoriness in TP53 wild-type chronic lymphocytic leukemia. Blood. 2012:119(12):2854-62. doi:10.1182/blood-2011-12-395673.

28. Rossi D, Deaglio S, Dominguez-Sola D, Rasi S, Vaisitti T, Agostinelli C, Spina V, Bruscaggin A, Monti S, Cerri M, Cresta S, Fangazio M, Arcaini L, Lucioni M Marasca R, Thieblemont C, Capello D, Facchetti F, Kwee I, Pileri SA, Foa R, Bertoni F, Dalla-Favera R, Pasqualucci L, Gaidano G. Alteration of BIRC3 and multiple other NF-kappaB pathway genes in splenic marginal zone lymphoma. Blood. 2011;118(18):4930-4. doi:10.1182/blood-2011-06-359166.

29. Yang Y, Kelly P, Shaffer AL, 3rd, Schmitz R, Yoo HM, Liu X, Huang da W, Webster D, Young RM, Nakagawa M, Ceribelli M, Wright GW, Yang Y, Zhao H, Yu X, Xu W, Chan WC, Jaffe ES, Gascoyne RD, Campo E, Rosenwald A, Ott G, Delabie J, Rimsza L, Staudt LM. Targeting non-proteolytic protein ubiquitination for the treatment of diffuse large B cell lymphoma. Cancer cell. (2016);29(4):494-507. doi:10.1016/j.ccell.2016.03.006

30. Yamaguchi $\mathrm{H}$, Hung MC. Regulation and role of $\mathrm{EZH} 2$ in cancer. Cancer res treat. 2014;46(3):209-22. doi:10.4143/crt.2014.46.3.209.

31. Herviou L, Cavalli G, Cartron G, Klein B, Moreaux J. EZH2 in normal hematopoiesis and hematological malignancies. Oncotarget. 2016;7(3): 2284-96. 10.18632/oncotarget.6198.

32. Morin RD, Johnson NA, Severson TM, Mungall AJ, An J, Goya R, Paul JE, Boyle M, Woolcock BW, Kuchenbauer F, Yap D, Humphries RK, Griffith OL, Shah S, Zhu H, Kimbara M, Shashkin P, Charlot JF, Tcherpakov M, Corbett R, Tam A, Varhol R, Smailus D, Moksa M, Zhao Y, Delaney A, Qian H, Birol I, Schein J, Moore R, Holt R, Horsman DE, Connors JM, Jones S, Aparicio S, Hirst M, Gascoyne RD, Marra MA. Somatic mutations altering EZH2 (Tyr641) in follicular and diffuse large B-cell lymphomas of germinal-center origin. Nat genet. (2010);42(2):181-185. doi:10.1038/ng.518

33. Kim KH, Roberts CW. Targeting EZH2 in cancer. Nat med. 2016:22(2):128-34. doi:10.1038/nm.4036.

34. McCabe MT, Ott HM, Ganji G, Korenchuk S, Thompson C, Van Aller GS, Liu Y, Graves AP, Della Pietra 3rd A, Diaz E, Lafrance LV, Mellinger M, Duquenne C, Tian X, Kruger RG, Mchugh CF, Brandt M, Miller WH, Dhanak D, Verma SK, Tummino PJ, Creasy CL. EZH2 inhibition as a therapeutic strategy for lymphoma with EZH2-activating mutations. Nature. 2012;492(7427):108-12. doi:10.1038/nature11606. 
35. Yu YL, Su KJ, Hsieh YH, Lee HL, Chen TY, Hsiao PC, Yang SF. Effects of EZH2 polymorphisms on susceptibility to and pathological development of hepatocellular carcinoma. Plos one. 2013;8(9):e74870. doi:10.1371/journal. pone.0074870

36. Paolicchi E, Pacetti P, Giovannetti E, Mambrini A, Orlandi M, Crea F, Romani AA, Tartarini R, Danesi R, Peters GJ, Cantore M. A single nucleotide polymorphism in $\mathrm{EZH} 2$ predicts overall survival rate in patients with cholangiocarcinoma. Oncol lett. 2013;6(5):1487-91. doi:10.3892/ol.2013.1559.

37. Ma ZB, Guo GH, Niu Q, Shi N. Role of EZH2 polymorphisms in esophageal squamous cell carcinoma risk in Han Chinese population. Int j mol sci. 2014; 15(7):12688-97. doi:10.3390/ijms150712688.

38. Yu YL, Su KJ, Hsieh MJ, Wang SS, Wang PH, Weng WC, Yang SF. Impact of EZH2 polymorphisms on urothelial cell carcinoma susceptibility and clinicopathologic features. Plos one. 2014;9(4):e93635. doi:10.1371/journal. pone.0093635

Submit your next manuscript to BioMed Central and we will help you at every step:

- We accept pre-submission inquiries

- Our selector tool helps you to find the most relevant journal

- We provide round the clock customer support

- Convenient online submission

- Thorough peer review

- Inclusion in PubMed and all major indexing services

- Maximum visibility for your research

Submit your manuscript at www.biomedcentral.com/submit
Biomed Central 